\title{
Baccalaureate-linked oncology nursing education: McMaster University's Paediatric and Adult Oncology Nursing Program
}

By Barbara Love

\begin{abstract}
For new nursing graduates prepared as generalists, the transition from student to graduate and from new generalist graduate to experienced specialized nurse can be very anxiety-provoking. This paper discusses one program, the Oncology Nursing Program, McMaster University, designed for nurses working along the cancer continuum. Proposed by oncology nurses seeking baccalaureatelinked specialty education, the year-long program has now been in existence for 10 years. A cadre of nearly 200 graduates affirm that specialized education influences direct patient care, health care team membership, professional and personal development.
\end{abstract}

The transition from nursing student to new graduate is fraught with angst, (Boychuk, 2001; Brown \& Edelman, 2000; Charnley, 1999; Heslop, McIntyre, \& Ives, 2001; McConnell \& Dadish, 1997; Oermann \& Garvin, 2002; Oermann \& Moffitt-Wolf, 1997), in part, because universities and colleges prepare their graduates to practise at a generic level, when the real world of nursing is predominantly one of specialization. The new graduate, a generalist nurse, is able to invoke the nursing process, but requires substantial support with more complex or specialized clinical issues (Meraviglia, McGuire \& Chesley, 2003).

The literature abounds with indicators of the benefits of specialized nursing practice, but the path to the acquisition of specialized status is uncharted, with few discernible benchmarks of success in knowledge and skill acquisition. By exploring one specialty, oncology nursing, the benefits of specialization and an educational route to specialized status, a template may be available to others.

\section{Specialized oncology nursing}

For the purposes of this article, the definitions suggested in the Standards of Care for Individuals with Cancer, Nursing Roles and Role Competencies Document (CANO, 2001) will be utilized.

The generalist nurse may be a new graduate or a nurse unfamiliar with the practice of cancer care. He/she has yet to acquire the knowledge and clinical expertise in a setting where the primary focus is care of the individual with cancer and their family. The nurse may have specialized knowledge in another focus (e.g. emergency care) and be deemed a specialized nurse in that area, but amongst the population of care recipients of this nurse, the individual with cancer is only one (CANO, 2001, p. 27).

The specialized oncology nurse has a combination of expanded education focused on cancer care and experience in a setting where the primary focus is cancer care delivery. This nurse has recognized competency in knowledge, clinical skills, cognitive skills and application process (CANO, 2001, p. 27).

The advanced oncology nurse is prepared at the Master's level and his/her practice domains would include advanced practice care, education, research, scholarly/professional leadership and organizational leadership (CANO, 2001, p. 28).
CANO (2001) acknowledges that whether generalist, specialized oncology or advanced oncology nurse, each individual nurse moves along a trajectory from novice to expert (Benner, 1984). The degree of expertise achieved is influenced by the nurse's ongoing learning and day-to-day practice experiences (CANO, 2001, p. 28).

\section{The benefits of specialized oncology nursing}

For individuals with cancer and their families, there is substantial evidence of benefit when care is provided by a specialized oncology nurse. Specialized oncology nurses have been found to improve the health outcomes of patients related to pain and symptom management, psychosocial well-being, quality of life, treatment outcomes, uses of health promotion strategies, selfcare and treatment compliance and patient knowledge regarding their disease and treatment (Bredin et al., 1999; Corner et al., 2003; Corner et al., 1996; Faithfull et al., 2001; Hegelson et al., 2000; Loftus \& Weston, 2001; McCorkle et al., 1989; Radwin, 2000). In addition, specialized oncology nursing care is associated with reduced health care costs, decreased hospital admissions, improved quality of care, increased patient satisfaction with care, and nurse and health care provider job satisfaction (Aiken et al., 2003; Aiken, Clarke \& Sloane, 2002; Aiken et al., 2002; Ferrell, Virani, Smith \& Juarez, 2003; Ritz et al., 2000).

\section{Transitioning from generalist to specialized oncology nurse}

Clearly, for the individual with cancer and their family, exposure to a specialized oncology nurse has benefit. Further, for institutions and agencies providing oncology services, there is substantial incentive to care provision by specialized oncology nurses. How then, does a new graduate transition from generic preparation and generalist role to specialized oncology nursing role status?

A review of the literature notes a variety of oncology nursing programs available: some within undergraduate curriculum (Bryant Lukosius, Love, Ingram \& Rideout, 1996; Logan, De Grasse, Stacey, Fiset, \& Fawcett, 1999; Musgrave, 1997; Nibert,

Barbara Love, BScN, MHSc, CON $(C)$, is Assistant Professor, Chair: Paediatric and Adult Oncology Nursing Program, Director: Gender and Health Initiatives at McMaster University, Hamilton, $O N$.

CONJ is delighted to include, following this article by Barbara Love, three papers written by graduates of the McMaster adult oncology program about their reflections on their experience of this program. The thoughts and words of these oncology nurses are an inspiration, and a validation of the value of such programs for oncology nurses.

Editor-in-Chief 
2000; Rushton, 1999; Sarna \& McCorkle, 1995; Savopoulou, 2001), some continuing education programs for graduate nurses (Ferrell, Grant, Borneman, Juarez \& Virani, 2002), some focused on oncology nurse practioner development (Rosenzweig, Hravnak \& Jacob, 1997), and some aimed at advanced practice in oncology nursing (Brown \& Hinds, 1998; Nelson-Marten, Skiba, Howell, \& Krebs, 1997).

Some of the fore-mentioned programs have been evaluated; many have not. Langton's extensive review of more than 340 English National Board post-registration cancer nursing and palliative care courses highlighted the current strengths and gaps in oncology nursing education programs in Britain (Langton, 1999, Hek, Langton $\&$ Blunden, 2000). A review of this magnitude has not occurred in Canada.

In Canada, the path from generalist to specialized oncology nurse has typically occurred through work-site orientation and apprenticeship, demonstration models, workshop attendance or continuing education programs that are generally not accredited. Since 1996, nurses with two years of clinical practice in oncology nursing can apply to write a national certification examination prepared by the Canadian Nurses Association. More recently, primarily because of pressure from the specialty itself, oncology nursing courses are beginning to appear within undergraduate, postbasic and graduate curriculum.

It would seem that there are multiple routes to the acquisition of specialized status, but little consensus or evaluative data to clarify the path of choice (McGuire, 1997; Mooney, 2000; Workman, 1996), leaving those seeking direction somewhat befuddled.

\section{The McMaster Oncology Nursing Education Program}

In the 1980s, the majority of practising oncology nurses in Ontario were college- or hospital-prepared. (Legislation requires baccalaureate as entry to practice in 2005). In-depth, specialized preparation was at the discretion of the individual nurse and his/her employer.

In 1988, the nursing committee of the Paediatric Oncology Group of Ontario (POGO) identified the need for rigorous, standardized, comprehensive, baccalaureate-level paediatric oncology nursing education as a priority. In 1992, POGO began working with a nurse educator to develop a curriculum in partnership with a university school of nursing (Lindsay, 1995). Funding was obtained from two foundations that supported the quest for excellence in practice and research-based nursing care.

McMaster University nursing faculty saw the benefit of this education to nurses and their clients - children with cancer and their families - and a partnership was formed. Additional funding was obtained to support the initial development, implementation and evaluation of a paediatric oncology nursing curriculum.

A parallel development had been occurring in the area of adult oncology nursing. In 1993, oncology nurses at the Henderson Hospital in Hamilton, Ontario, expressed their desire for credible education that recognized nursing's specialized, unique, and important contributions to cancer care. In response to this need, a group of nurse educators and administrators from the Henderson Hospital, the Hamilton Regional Cancer Centre and McMaster University began meeting to explore this issue and develop possible solutions.

Through their efforts, the Hamilton Committee recognized that the need for rigorous and academic education in adult oncology nursing was more than just a local issue. In November 1994, a Provincial Steering Committee, in partnership with McMaster University, was established to develop a university-based adult oncology nursing program.
In 1994, the first class of 16 initiated the Paediatric Oncology Nursing Program under the stewardship of BL., the current program coordinator. Two years later, the Adult Oncology Nursing Program was launched, under Denise Bryant Lukosius's directorship, and both programs remain viable at the current time. Although most student enrolees had participated in continuing education, few had engaged in university level education prior to enrolment in the program.

\section{Recruitment and application process}

Oncology program faculty are visible within the provincial and national oncology organizations (POGO and CANO) and readily available to respond to questions about the program. In addition, advisory board members are linked to clinical institutions in managerial, educational and consultative capacities. Faculty initially visited potential sites to advertise the program, but this process was time and resource consuming and felt to have limited value. Perhaps the most fruitful advertisement is the product - the nurse graduates who share their learning and excitement with others.

The application process is rigorous and patterned after the McMaster post-basic baccalaureates program, except that oncology nursing applicants do not require evidence of success at the university level. In fact, students are not formally enrolled in the baccalaureate program unless they choose to do so. Applicants submit transcripts from previous learning institutions, references, and an essay responding to three questions. The essay questions seek to determine the applicant's knowledge of the McMaster pedagogical philosophy, their ability to critique their own practice and to critically reflect. References from two colleagues are submitted independently. All submitted data are assessed and collated by independent practitioners using criteria developed by the university. Only individuals scoring above a pre-specified level are admitted to the program.

Because of a dearth of baccalaureate-linked specialized nursing education programs, some student participants have commuted from distances greater than 700 kilometres. Distance education supports have been made available since the program's inception (including video and tele-conferencing, consultation from local university faculty and, more recently, synchronous and asynchronous web-based programs), but students persist in pursuing their education in a route that allows them regular face-toface support. In addition, because nurses from multiple education backgrounds are seeking oncology-focused education, the student enrolees may have hospital, college, university, or graduate school preparation.

\section{Entry process}

A strong supportive climate is prepared to welcome and orient the nurse-students to their new learning environment. Letters of admission are encouraging and the initial day of orientation seeks to diminish entry anxiety, maximize group acclimatization and coach for success.

The program is organized so that students attend classes one day a week, over three consecutive semesters, participating in a morning and afternoon class. The classes are typically held on the university campus, in the Health Science Centre. This avails the students of the academic climate and resources (e.g., libraries, laboratories) important to the transition in their thinking. Visiting faculty may join the class or day trips occur to meet learning needs (e.g., radiation centres). Many students continue to work full-time, although they find the workload very heavy and often require coaching about "coping with change" (Woods, 1994). Faculty have recognized that extra 'nurturing' is essential in the first semester so time is allocated for research skills, information 
management, paper writing and 'letting off steam'. The group itself becomes a 'community of support' and very few students have entered and not completed the program. Serious illness has been the cited reason for non-completion.

\section{Educational philosophy}

McMaster University's Health Science Faculty use an androgogical model first described by Malcolm Knowles (1975), but adapted to health care education by two McMaster faculty (Barrows \& Tamblyn, 1980). Students converge in small groups (eight to 12 students) and, tutored by a facilitator familiar with the process, use pre-established problem (or issue) scenarios and a process called "problem-based learning" (Barrows, 1988; Rideout, 2001). Вy exploring the problem, and determining issues that are "known", "unknown" and "need to be known", the students emerge with a composite of learning issues. These are assigned amongst the group, independently researched and presented to the group on a subsequent week. The tutor facilitates the process by encouraging in-depth discussion of the arising issues.

Typically, an oncology problem might pattern the continuum of cancer as it emerges for an individual (e.g., early symptoms, to heightened awareness, to investigations, to diagnosis, to treatment, to response, etc.). Usually, experienced nurses will read the problem and propose a 'diagnosis', then want to focus on the interventions. The tutor extends the critical thinking process by asking for "the physiologic basis of fever" or "five hypotheses for the presenting symptomatology". By challenging for depth and breadth, the tutor facilitates a critical thinking process (AlfaroLeFevre, 1995).

For the majority of enrolees, previous formal learning has occurred in didactic frameworks with the teacher or "knower" telling the student what they needed to know and then providing that information in a lecture format. That traditional pedagogical model is familiar and comforting. The "new" problem-based mode is very anxiety provoking and many students experience an initial disorientation, a subsequent "perspective-taking" and, ultimately, choose to engage in the new learning style (Mezirow, 1990). The strong camaraderie fostered during the small group development aids in the adaptation and contractual commitment to the educational process, the group learning and the intrapersonal changes (Brookfield, 1993; Callin, 1996; Mezirow, 1990; SavinBaden, 2000).

\section{Course content}

The first semester begins with a generalized orientation, some beginning group work and courses focused on theory and communication.

Concepts and Theories in Oncology Nursing I uses the forementioned problem-based modality to focus on the impact of cancer related to diagnosis, treatment, recurrence, supportive care, palliation, bereavement and loss, rehabilitation and survivorship. Evaluative components include tutorial participation, achievement of a learning objective, a presentation related to review of the student's practice using critical thinking modalities and a written submission integrating theoretical perspectives with their own performance in the group, as recorded on videotape.

Communication Skills for Individuals, Families and Communities supports the development of advanced therapeutic communication skills relevant to the complex nursing care of individuals with cancer, their families and communities. Using standardized simulated patients, (Rideout, 2001), students "rehearse" interventions that had been discussed theoretically (e.g., a family interview with a husband and his 34-year-old wife who has advanced squamous cell carcinoma of the lung and is dying). Evaluation is based on tutorial participation and several papers incorporating intense reflection of self, and interviews with colleagues, clients and their family incorporating application of theoretical models.

In second semester, students participate in an oncology focused assessment course and a research course.

Oncology Health Assessment entails the application of knowledge of anatomy, physiology, assessment principles, human behaviour and growth and development in analyzing client data and demonstration of a logical and comprehensive approach to history-taking, as well as accurate physical examination techniques in performing a client-centred assessment. Short preassigned client scenarios are analysed in advance, then discussed in tutorial with students vying to determine maximum potential diagnoses with supporting rationale. The scenarios provide fodder for focus in prevention, screening and early detection, protective mechanisms, circulation, respiration, locomotion, sexuality, comfort and coping. The tutor, in conjunction with expert guest faculty (advanced practice nurses, residents and specialized physicians), then provide demonstration, return-demonstration practice with students in history-taking and physical assessment techniques relevant to emergent oncology issues. Evaluation is based on tutorial preparation and participation, written submission of two focused and one comprehensive assessment completed at their home site under the supervision of an advanced oncology clinician and an objective standardized clinical evaluation (OSCE) (Rideout, 2001).

Research Methods and Critical Appraisal introduces students to the methodological principles of clinical research and statistical inference with particular emphasis on the critical assessment of research evidence (qualitative and quantitative) as presented in the health science literature generally and oncology nursing specifically. On a weekly basis, pre-selected articles are reviewed for methodological rigour and applicability to practice. In a final evaluative component, students choose an issue of relevance to their clinical site, refine a research question, execute a literature search and review in depth three to five emergent articles. A comprehensive analysis of the findings is presented to the class with recommendations for practice.

Third semester consolidates much of the learning to date. A second theory course and a clinical practicum consolidate earlier learning.

Concepts and Theories in Oncology Nursing II provides learners with the opportunity to demonstrate teaching learning principles as they lead their peers through a "case" gleaned from their clinical site. Students continue to explore issues along the cancer continuum integrating theoretical postulates to broaden and deepen their grasp of client and professional reality. Best practice literature is heavily integrated into the case studies. Evaluation is based on tutorial preparation, leadership and participation, a written paper and a group exercise requiring the dissemination and application of best-practice guidelines to change practice in response to a hypothetical oncology issue.

Oncology Nursing Practice, an applied nursing practice course, focuses on the integration of theories and concepts. Emphasis is on the development of knowledge and expanded role skills related to cancer and the well-being of clients, families and communities including health education, cancer prevention, early detection, client and family assessment treatment and support. The clinical experience is obtained at cancer centres, hospitals, clinics, hospices and community service centres locally, nationally and internationally. Specialized or advanced oncology nurses experienced in the focused area, act as preceptors and students interact with university faculty to facilitate participation in and observation of oncology nursing roles related to screening, diagnosing, and treating patients and families throughout the cancer care continuum. Opportunities are tailored to individual nurse learning goals. Projects are enacted by the nurse-learners that benefit themselves and the hosting/home site. 


\section{Outcomes of oncology education at McMaster University}

As the first contingent of students (paediatric: 1994, and adult: 1996) entered the program, they participated in a formal baseline evaluation. A similar appraisal was conducted as they exited one year later. The three-part, day-long examination of knowledge, skills and communication encompassed multiple choice questions, and objective structured clinical evaluations (OSCE) (Rideout, 2001). All evaluation tools were constructed by an international panel of independent oncology specialized examiners. In all three examined areas, significant change was noted.

A 1999 mailed survey to all Oncology Nursing Program graduates from 1994-1999 (Rideout \& Love, 2000) reviewed the status of program graduates ( $72 \%$ response rate). Of the respondents who had completed the Paediatric Oncology Program, $76 \%$ of the nurses were enrolled in or had completed baccalaureate nursing programs, and a majority of those were attending McMaster University. Similar findings were evident in the respondents from the Adult Oncology data, with $71 \%$ t of the nurses having either completed or enrolled in baccalaureate nursing programs, most at McMaster University.

Sixty-eight per cent of the paediatric graduates and $83 \%$ of the adult graduates continued to work in oncology, either in-patient, outpatient or community settings. The majority of nurses not working in oncology continued to be employed in nursing, often in oncologyrelated roles. Several nurses had moved into management positions and several others had moved into settings deemed 'higher status', as a consequence of completing the program.

High levels of satisfaction were expressed by most respondents, and the chief source of satisfaction came from interactions with patients and their families. The nurses commented in particular on the satisfaction derived from advocating and teaching patients, and having a sense of contributing to their care. Autonomy and independence at work and as health professionals were also noted as positive aspects for some nurses. Sources of dissatisfaction were related almost exclusively to what might be called environmental issues, including the lack of time, staff, support and collegiality in some positions. Although many nurses voiced concerns, none indicated that they planned to leave the profession.

Finally, the nurses indicated a strong sense of educational preparation for their roles in oncology nursing. They perceived strong decision-making abilities; they noted high levels of preparation in communication, teaching, group process, critical thinking and selfdirected learning. Lower levels of preparation were related to new and fast changing treatment modalities, and preventive and rehabilitation aspects of cancer care (Rideout and Love, 2000).

To date (July, 2004), 202 nurses (66 Paediatric, 136 Adult) have enrolled in the McMaster University Oncology Nursing Program, including 12 sponsored by the Ministry of Health, Trinidad and Tobago. At the point of enrolment, most students expressed angst about returning to school, but felt the need to do so "for their patients". Although students were under no obligation from the university or their workplace to transfer into baccalaureate programs, many have done so. Because the Oncology Program is novel to the province, some students chose to travel great distances to participate. By networking with other baccalaureate nursing programs in the province, students are assured transition of credits, allowing them to complete their degrees in more regional university sites. In fact, over $75 \%$ are enrolled in or have completed their baccalaureate degree and 28 students are currently enrolled in or have completed their Master's degree. The vast majority of students have remained in an oncology practice, functioning at the specialized oncology nurse level.

\section{Planning for the future}

The absence of formal pathways from generalist to specialized nursing practice creates credentialing difficulty for clients, nurses and employers. To date, the best assurance of content knowledge at one point in time has been the certification examination. As baccalaureate-as-entry-to-practice becomes a reality, the methodologies to accessing specialized knowledge and skill may require re-thinking. In the event of nursing shortages, specialty areas will compete to recruit generalists or specialized nurses from other foci, who will require clinical and academic support to gain specialized capacity. Further, to retain these new recruits will require innovative and capacity-building acumen. If these individuals are prepared at the baccalaureate level, what kind of academic interventions will they want and what acknowledgement will they expect for their efforts? What programming will employers support and how will the effectiveness of the program be evaluated for the nurse-learner, the employing institution, and the care recipients? Within the academic world, nurses can achieve baccalaureate, Master's and doctoral status. The clinical nomenclatures, generalist, specialized and advanced nurse (CANO, 2001) are not equivalent. Should universities engage in post-baccalaureate, pre-Master's education that would support clinicians seeking interim level education? Or is specialized education the responsibility of care facilities? Or should academic institutions liaise with care providers to develop a new model of education? Should specialized education programs be developed for local or national consumption (Tomlinson, 2004)? McMaster University is currently investigating post-baccalaureate, Master's linked oncology nursing education in partnership with care providers across the province.

Based on the McMaster model, one might speculate that supportive specialized education promotes commitment to the specialty of oncology nursing. Further research could potentially investigate this postulate. The enactment of a randomized control study evaluating patient outcomes when exposed to nurses who had participated in specialty education versus nurses who were scheduled to enact in such programs would provide more definitive evidence for the utility of such educational programs for clients, clinicians and institutions or agencies.

The need for increased access to education cannot be overstated. The literature abounds with the impact of education on professionalism (Love, Green \& Bryant Lukosius, 2004) and patient outcomes (Aiken, Clarke Cheung, Sloane \& Silber, 2003; Aiken, Clarke \& Sloane, 2002; Aiken, Clarke, Sloane, Sochalski \& Silber, 2002).

The literature is clear that care of individuals with cancer and their families by specialized oncology nurses is beneficial for both the recipients and providers of care. The route to acquisition of the specialized knowledge required to enact the focused role is, to date, ill-defined and poorly enacted. By defining the success of one program, potential exists to emulate or further investigate specialized nursing education programs. Predicted nursing shortages support the urgency for professional and academic collaboration to further clarify transitional issues, propose innovative solutions, mount and evaluate the interventions.

\section{Acknowledgement}

This paper is dedicated, with admiration, to the unremitting commitment of Esther Green, Denise Bryant Lukosius, Lorna Butler, Janet Gammon, Carolyn Ingram, Cathy Bennett, Andrea Miller and Janie Lappin, tireless champions of Canadian oncology nurses, education and excellence in all things. 
Aiken, L.H., Clarke, S.P., Cheung, R.B., Sloane, D.M., \& Silber, J.H. (2003). Educational levels of hospital nurses and surgical patient mortality. Journal of the American Medical Association, 290(12), 1617-23.

Aiken, L., Clarke, S., \& Sloane, D. (2002). Hospital staffing, organization, and quality of care: Cross national findings. International Journal for Quality in Health Care, 14, 5-13.

Aiken, L., Clarke, S., Sloane, D., Sochalski, J., \& Silber, J. (2002). Hospital nurse staffing and patient mortality, nurse burnout and job satisfaction. Journal of the American Medical Association, 288, 1987-1993.

Alfaro-LeFevre, R. (1995). Critical Thinking in Nursing. Philadelphia: W. B. Saunders.

Barrows, H. (1988). The Tutorial Process. Springfield IL: Southern Illinois University, School of Medicine.

Barrows, H., \& Tamblyn, R. (1980). Problem-Based Learning. New York: P.S. Springer- Verlag.

Benner, P.(1984). From novice to expert: Excellence and power in clinical nursing practice. Menlo Park, CA: Addison-Wesley.

Boychuk, J. (2001). Out in the real world: Newly graduated nurses in acute-care speak out. Journal of Nursing Administration, 31(9), 426-439.

Bredin, M., Corner, J., Krishansanmy, M., Plant, H., Bailey, C., \& A'Hern, R. (1999). Multicentre randomized controlled trial of nursing interventions for breathlessness in patients with lung cancer. British Medical Journal, 318, 901-904.

Brookfield, S. (1993). On impostership, cultural suicide and other dangers: How nurses learn critical thinking. Journal of Continuing Education in Nursing, 24(5), 197-205.

Brown, H., \& Edelman, R. (2000). Project 2000: A study of expected and experienced stressors and support reported by students and qualified nurses. Journal of Advanced Nursing, 31(4), 857-864.

Brown, J., \& Hinds, P. (1998). Assessing master's programmes in advanced practice oncology nursing. Oncology Nursing Forum, 25(8), 1433-4.

Bryant Lukosius, D., Love, B., Ingram, C., \& Rideout, E. (1996). Baccalaureate education in nursing: The dream is becoming a reality for Ontario nurses. Canadian Oncology Nursing Journal, 6(1) 49-51.

Callin, M. (1996). From RN to BScN: Seeing familiar situations in new ways. Journal of Continuing Education in Nursing, 27(1), 28-33.

Canadian Association of Nurses in Oncology/Association canadienne des infirmières en oncology (CANO/ACIO). (2001). Standards of care, roles in oncology nursing and role competencies. Toronto, ON: Author.

Charnley, E. (1999). Occupational stress in the newly qualified staff nurses. Nursing Standard, 13, 29, 32-36.

Corner, J., Halliday, D., Haviland, J., Douglas, H.R., Bath, P., Clark, D., Normand, C., Beech, N., Hughes, B., Marples, R., Seymour, J., Skilbeck, J., \& Webb, T. (2003). Exploring nursing outcomes for patients with advanced cancer following intervention by Macmillan specialist palliative care nurses. Journal of Advanced Nursing, 41(6), 561-574.

Corner, J., Plant, H., A’Hern, R., \& Baile, C. (1996). Nonpharmacologic intervention for breathlessness in lung cancer. International Journal of Palliative Care Nursing, 1, 5-10.

Faithfull, S., Corner, J., Meyer, L., Huddart, R., \& Dearnaley, D. (2001). Evaluation of nurse-led follow up for patients undergoing pelvic radiotherapy. British Journal of Cancer, 85(12), 1853-64.

Ferrell, B., Virani, R., Smith, S., \& Juarez G.: National Cancer Policy Board and Institute of Medicine. (2003). The role of oncology nursing to ensure quality care for cancer survivors: A report commissioned by the National Cancer Policy Board and Institute of Medicine. Oncology Nursing Forum, 30(1) E1-E11.
Ferrell, B., Grant, M., Borneman, T., Juarez, G., \& Virani, R. (2002). Strategies for effective continuing education by oncology nurses. Oncology Nursing Forum, 29(6), 907-9.

Hegelson, F., Andersson, S., Gustafsson, O., Varenhorst, E., Goben, B., Carnock, S., Sehlstedt, L., Carlsson, P., Holmberg, L., \& Hohansson, J. (2000). Follow-up of prostate cancer patients by ondemand contacts with a specialist nurse. Scandinavian Journal of Urology and Nephrology, 34, 55-61.

Hek, G., Langton, H., \& Blunden, G. (2000). Cancer nursing education. Nursing Standard, 14(21), 23.

Heslop, L., McIntyre, M., \& Ives, G., (2001). Undergraduate student nurses expectations and their self-reported preparedness for the graduate year role. Journal of Advanced Nursing, 36(5), 626-634.

Knowles, M. (1975). Self-directed Learning: A Guide for Learners and Teachers. New York: Association Press.

Langton, H. (1999). Cancer Nursing Education Literature Review and Documentary Analysis. London: English National Board.

Lindsay, G. (1995). Observations on introducing a paediatric oncology nursing focus in a post-RN BScN program. Canadian Oncology Nursing Journal, 5(2), 41-44.

Loftus, L., \& Weston, V. (2001). The development of nurse-led clinics in cancer care. Journal of Clinical Nursing, 10, 215-220.

Logan, J., De Grasse, C., Stacey, D., Fiset, V., \& Fawcett, L. (1999). Oncology nursing education within a supportive care framework: An evidence-based undergraduate course. Canadian Oncology Nursing Journal, 9(2) 64-70.

Love, B., Green, E., \& Bryant Lukosius, D. (2004). Oncology Nursing: Our past is the prologue. Can we author the future? Canadian Oncology Nursing Journal, 14(2), 96-102.

McConnell, E., \& Dadish, K. (1997). Concerns of graduating baccalaureate nursing students. Nursing Connections, 10(3), 15-27.

McCorkle, R., Benoliel, J., Donaldson, G., Georiadou, F., Moinpour, C., \& Goodall, B. (1989). A randomized control trial of home nursing care for lung cancer patients. Cancer, 64(6), 1375-82.

McGuire, D. (1997). Cancer education: Challenges of the present: oncology nursing. Journal of Cancer Education, 12(1), 20-3.

Meraviglia, M., McGuire, C., \& Chesley, D. (2003). Nurse's need for education on cancer and end-of-life care. Journal of Continuing Education in Nursing, 34(3), 122-127.

Mezirow, J. (1990). Fostering Critical Reflection in Adulthood: A Guide to Transformative and Emancipatory Learning. San Francisco: Jossey-Bass.

Mooney, K. (2000). Oncology nursing education: Peril and opportunities in the new century. Seminars in Oncology Nursing, 16(1), 25-34.

Musgrave, C. (1997). An oncology clinical experience in an Israeli baccalaureate nursing programme. Journal of Nursing Education, 36(7), 337-9.

Nelson-Marten, P., Skiba, D., Howell, S., \& Krebs, L. (1997). An innovative curriculum plan for advanced practice in oncology nursing. Journal of Cancer Education, 12(2), 89-94.

Nibert, A. (2000). Incorporating critical care oncology nursing in a baccalaureate of science in nursing curriculum. Critical Care Nursing Clinics of North America, 12(3), 391-5.

Oermann, M., \& Garvin, M. (2002). Stresses and challenges for new graduates in Hospitals. Nurse Education Today, 2, 225-230.

Oermann, M., \& Moffitt-Wolf, A. (1997). New graduates' perceptions of clinical practice. Journal of Continuing Education in Nursing, 28(1), 20-25.

Radwin, L. (2000). Oncology patients' perceptions of quality nursing care. Research in Nursing \& Health, 23, 179-190.

Rideout, E. (2001). Transforming Nursing Education through Problem-Based Learning. Toronto: Jones and Bartlett Publishers. 
Rideout, E., \& Love, B. (2000). Evaluation of Paediatric and Adult Oncology Nursing Programme. Hamilton, ON: McMaster University.

Ritz, L., Nissen, M., Swenson, K., Farrell, J., Sperduto, P., Sladek, M., Laly, R., \& Schroeder, M. (2000). Effects of advanced nursing care on quality of life and cost outcomes of women diagnosed with breast cancer. Oncology Nursing Forum, 27(6), 923-32.

Rosenzweig, M., Hravnak, M., \& Jacob, H. (1997). One school's experience with the development of an oncology nurse practioner curriculum. Oncology Nursing Forum, 24(5) 845-51.

Rushton, P. (1999). An undergraduate oncology nursing course. Oncology Nursing Forum, 26(1) 75-79.

Sarna, I., \& McCorkle, R. (1995). A cancer nursing curriculum guide for baccalaureate nursing education. Cancer Nursing, 18(6) 445-6.
Savin-Baden, M. (2000). Problem-based learning in higher education: Untold stories. Philadelphia: The Society for Research into Higher Education and Open University Press.

Savopoulou, G., (2001). Undergraduate oncology nursing education in the Balkans and the Middle East. Journal of Cancer Education, 16(3), 139-141.

Tomlinson, D. (2004) Paediatric oncology nurse education: the development of a national framework. Journal of Clinical Nursing 13, 646-654.

Woods, D. (1994). Problem-based learning: How to get the most from PBL. Waterdown, ON: Donald R. Woods.

Workman, M. (1996). Oncology nursing education. Annual Review of Nursing Research, 14, 167-78.

\section{Reflection on the McMaster Adult Oncology Program}

\section{By Linda Masko}

Can you teach an "old nurse" new tricks? You bet! In 1996, after 20 years in nursing, I was accepted into the Adult Oncology Program at McMaster University. This was a day that changed my life both personally and professionally and I have never looked back!

As I stepped through the door on the first day, I remember wondering what a nurse from a 50-bed rural northern Ontario hospital could possibly have to offer, or how I would ever succeed in the program. My anxieties were quickly put to rest. What an opportunity this created for tertiary care nurses to learn about providing care in small centres and, conversely, what an awakening for the community and rural nurse. This program prepared me to take my place in the whole continuum of care that cancer patients and their families require. It built on my knowledge and that of my colleagues in the course and supplemented that experience with scholarly skills, evidence-based practice, critical thinking and research.

This program taught me how to spread and stretch my wings. Since graduation, I have presented research work at the national and international level, received national certification in two specialties and published an article. A personal achievement is coming true this spring as, like many of my colleagues from this program, I have finally completed my degree in nursing. I attribute all my professional accomplishments to this program.

With a tear in my eye and from the bottom of my heart, I have to thank Barb Love and Denise Bryant Lukosius for providing a program that truly has changed my oncology nursing practice over the past eight years. What's in my heart is hard to put into words!
The lyrics from one of Celine Dion's songs can only describe my feelings of the true essence of oncology nursing and what Barb, Denise and my fellow students have done for me.

\footnotetext{
"You saw the best there was in me Lifted me up when I couldn't reach You gave me faith 'coz you believed I'm everything I am

Because you loved me."
}

Linda Masko, RN, CON $(C), \operatorname{CINA}(C)$, completed the Adult Oncology Nursing Certificate Program at McMaster University in 1998 and will complete a $B S c N$ at Laurentian University in May, 2005. She is an Emergency Room Nurse/Train-the-trainer Nurse in the Oncology Clinic at West Nipissing General Hospital, Sturgeon Falls, ON (705) 753 3110 beeper 59 .

\section{Thoughts on the adult oncology program}

\section{By Betty Ann Griffiths}

Entering the adult oncology nursing program as a seasoned oncology nurse caused excitement and apprehension. More than 10 years of oncology experience, an oncology nursing certification with the Oncology Nursing Society, and completion of an oncology certification program at a community college had added substantially to my oncology nursing knowledge, but had not changed my clinical practice. What could I learn at the university level?

Learning during this year-long program was a difficult, but rewarding process. The professors encouraged me to think critically by continually asking us to question "why" rather than accepting information and problemsolving based on previous and similar clinical experiences. I learned to conduct literature searches and critically appraise the literature in addition to using texts, clinical experience, and experts in the field when preparing for discussion of case scenarios for class. The use of simulated patients in the clinical laboratory improved historytaking, physical assessment, and communication skills. Theory, new to most students, taught me how theoretical knowledge supports clinical decision-making.

The adult oncology nursing program has provided me with the opportunity to learn advanced clinical and theoretical skills that are now applied to the oncology population I serve in my work environment. My personal selfconfidence has increased, and improved patient care has resulted. The program also introduced me to role models who had completed advanced level nursing education and who demonstrated leadership in oncology nursing practice and education. This opportunity inspired a personal and professional desire to complete a $\mathrm{BScN}$ and a Master's degree in order to obtain an advanced practice nursing role.

Betty Ann Griffiths, RN, BScN, $\operatorname{MScN}(c)$, CON $(C)$, is an Advanced Practice Nurse in Supportive Care work at the Juravinski Cancer Centre. She can be reached at (905) 387-9495. 


\section{Challenges}

\section{Editor's Note:}

This is the valedictory address presented by the author, Susan Balca, at the tenth commencement of the Paediatric and Adult Oncology Nursing Program, McMaster University, held this past March 1, 2005.

\section{By Susan Balca}

I appreciate the opportunity to speak to all of you on behalf of those of us who can now proudly say that we have successfully completed the oncology nursing program. Public speaking is not my forte, so I ask that you please bear with me in what may prove to be quite a challenge and, in that aspect, be in keeping with the underlying theme of the program itself.

I will begin with words that are not my own: Winston Churchill once said, "Kites rise highest against the wind, not with it." With regard to this program, his thoughts mirror my own.

We are the foot soldiers on the front lines of nursing care. We work in the clinics, hospitals, communities, some all of the above and with all populations of patients. We wear our practical expertise as armour, our experiential knowledge as medals of honour. We come with confidence in our abilities, a sense of security that only decades of nursing experience can provide and, yet, at this stage of our careers, we waver, we are somehow restless, unsettled.

Some of us wish to make a change; to explore new areas, new patient populations or new experiences. Some of us want to initiate measures that would lead to career advancement. Some of us seek professional development, and some of us seek to secure our marketability in a profession that seemed to be continually demanding more. We are, after all, diploma nurses, in a world where 'BScN preferred' seems to be a statement emblazoned on every job posting.

One thing we all seem to have in common is the knowledge that the world of health care is rapidly changing. An evolution is taking place of which we are inherently a part. With new advances in medical technology and health care research, the nursing role itself is changing and, ready or not, we are along for the ride.

To be ready for this change in health care, we chose to take steps to ensure that we would not be swept along with the tide, but be able to ride the waves with continued confidence in our knowledge and abilities. We came (to the oncology nursing program) to be renovated, to upgrade our skills and education, and validate our expertise. For all of the aforementioned reasons and more, we came together here. We decided to return to school, and potentially approach a $\mathrm{BScN}$. The oncology nursing program was our first step.

It was a challenge to say the least. We did not get out of this course what we expected. We got much, much more.

We expected to be taught didactically by a 'nursing oncology expert' everything we could ever be expected to know about oncology nursing. We expected to be given lists, and charts of every possible oncology diagnosis, treatment side effect and emergency, to be sent home to study and memorize them only to return to promptly regurgitate them on written tests and practical examinations. And, after all of this, we expected to walk away from the course with all latest and greatest in oncology nursing skills and knowledge. Well, that's not quite how it went.

The first thing we learned was how to learn; how to think, to be exact. But not only how to think, also, why to think and when to think. We learned that learning is not in any way didactic, but active and interactive; a process as progressive, evolutionary and innovative as the health care environment to which we were preparing ourselves to return.

And so, learn we did. We learned that what we required was not just knowledge and practical skills specific to oncology, but skills that we could apply to any new nursing environment we might encounter. We learned how to demystify research and statistical analysis. We learned how to apply advances made in technology and medical research to our clinical practice and we learned that our ability to access, interpret, utilize and contribute to research is integral to the continued enhancement and promotion of nursing as a profession.

Perhaps most importantly, we learned to recognize the importance of professional development by exploring nursing at its roots, by analyzing the significance of theories that first defined and established the nursing role. They still apply today but, in many ways, have been removed/distilled from our current health care environment with the incorporation of new medical advances and technologies. We learned the necessity for all of us to strive to do all that we can to keep the 'care' in health care.

As I'm sure you've gathered by now, there were many, many challenges. You might be wondering how we ever reached this point today. For the answer, you need look no further than there (gesturing toward Barbara Love). Barbara Love must take full responsibility for this. Much, much more than just an instructor, or tutorial leader, Barb has been our mentor, our guide. She has done much more than 'teach' us. She has nurtured us with her wisdom, encouraged us with her kindness and empathy, motivated us and, yes, challenged us to constantly test what we believed to be the boundaries of our abilities.

But, believe it or not, there was yet one more challenge and, with it, one more lesson; this undoubtedly the most important. We learned that although each of us registered and attended this program independently and as an individual, we succeeded in our struggle to complete this program only with the support of others. We all know who these ' others' are - our families, children, spouses, co-workers and friends. Those we sacrificed as we studied; ignored, as we read, researched and typed into the wee hours of the morning. They were our strength, our support, our foundation. We realized it then, we know it now and we will never forget.

Yes, the past year-and-a-half has been very challenging for us all. As adults, parents, spouses and, ultimately, students, we have risen to meet these challenges and in doing so, have been raised, lifted to a higher level academically, professionally and personally.

That said, I leave you with these words of thought from Frank Outlaw:

"Watch your thoughts, they become your words.

Watch your words, they become your actions.

Watch your actions, they become your habits.

Watch your habits, they become your character.

Watch your character, it becomes your destiny."

Susan Balca, RN, is a part-time student at McMaster University in the post-diploma $B S c N$ program. Concurrently, she is employed part-time at the Juravinski Cancer Centre in Hamilton, Ontario, as a radiation oncology nurse in the JCC's newly developed brachytherapy department. 